\title{
A SHORT NOTE ABOUT ENERGY-EFFICIENCY PERFORMANCE OF THERMALLY COUPLED DISTILLATION SEQUENCES
}

\section{Juan Gabriel Segovia-Hernández ${ }^{1 *}$, Salvador Hernández ${ }^{1}$ and Arturo Jiménez ${ }^{2}$}

\author{
1. Universidad de Guanajuato, Facultad de Química, Noria Alta s/n, Guanajuato, Gto., México 36050 \\ 2. Instituto Tecnológico de Celaya, Departamento de Ingeniería Química, Av. Tecnológico y García Cubas s/n, \\ Celaya, Gto., México 38010
}

In this work, we present a comparative study of the energy-efficiency performance between conventional distillation sequences and thermally coupled distillation arrangements (TCDS) for the separation of ternary mixtures of hydrocarbons under the action of feedback control loops. The influence of the relative ease of separation of the feed mixture and its composition was analyzed. The feedback analysis was conducted through servo tests with individual changes in the set points for each of the three product streams. Standard PI controllers were used for each loop. The results show an apparent trend regarding the sequence with a better dynamic performance. Generally, TCDS options performed better for the control of the extreme components of the ternary mixture ( $A$ and $C$ ), while the conventional sequences offered a better dynamic behaviour for the control of the intermediate component (B). The only case in which there was a dominant structure for all control loops was when the feed contained low amounts of the intermediate component and the mixture had similar relative volatilities. The Petlyuk column provided the optimal choice in such case, which contradicts the general expectations regarding its control behaviour. In addition, the energy demands during the dynamic responses were significantly lower than those observed for the other distillation sequences. TCDS options, therefore, are not only more energy efficient than the conventional sequences, but there are cases in which they also offer better feedback control properties.

On présente dans ce travail une étude comparative de la performance d'efficacité d'énergétique entre les séquences de distillation conventionnelles et les configurations de distillation couplées thermiquement (TCDS) pour la séparation de mélanges ternaires d'hydrocarbures sous l'action de boucles de contrôle d'asservissement. L'influence de la facilité relative de séparation du mélange d'alimentation et de sa composition est analysée. L'analyse de rétroalimentation est réalisée grâce à des tests d'asservissement avec des changements individuels dans les points de consigne pour chacun des trois courants de produits. Des contrôleurs PI standards ont été utilisés pour chaque boucle. Les résultats montrent une tendance apparente pour la séquence ayant une meilleure performance dynamique. Généralement, les options TCDS sont meilleures pour le contrôle des composantes extrêmes du mélange ternaire (A et $C$ ), tandis que les séquences conventionnelles offrent un meilleur contrôle dynamique pour le contrôle de la composante intermédiaire (B). Le seul cas où il y a une structure dominante pour toutes les boucles de contrôle, c'est lorsque l'alimentation contenant de faibles quantités de la composante intermédiaire et le mélange ont la même volatilité relative. La colonne Petlyuk est le choix optimal dans un tel cas, ce qui contredit les attentes générales concernant son comportement de contrôle. En outre, les demandes d'énergie pendant les réponses dynamiques sont significativement plus faibles que celles observées pour les autres séquences de distillation. Ainsi, non seulement les options TCDS sont plus efficaces que les séquences conventionnelles, mais il y a des cas où elles offrent également de meilleures propriétés de contrôle d'asservissement.

Keywords: conventional distillation sequences, thermally coupled distillation, energy-efficiency performance

$\mathrm{D}$ istillation is a widely used separation method in the process industries and it is the largest energy consumer among individual process units. Improvement of energy efficiency in distillation systems is still an active research field. Among the issues concerned with the improvement of energy efficiency of distillation systems, the optimal design and synthesis of multicomponent distillation schemes is still one of the most challenging problems. For optimal design of distillation systems of multicomponent separations, thermally coupled distillation

\footnotetext{
* Author to whom correspondence may be addressed. E-mail address: gsegovia@quijote.ugto.mx
} 


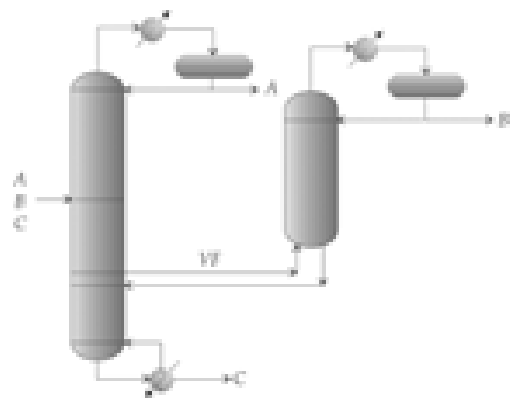

a) TCDS-SR

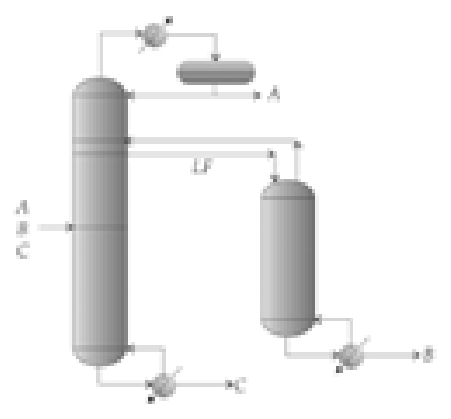

b) TCDS-sS

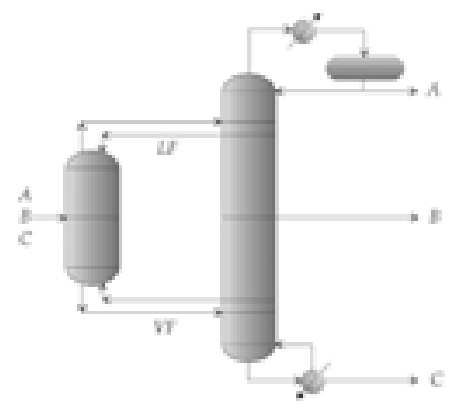

c) Petlyak Column

Figure 1. Thermally coupled distillation sequences for the separation of ternary mixtures

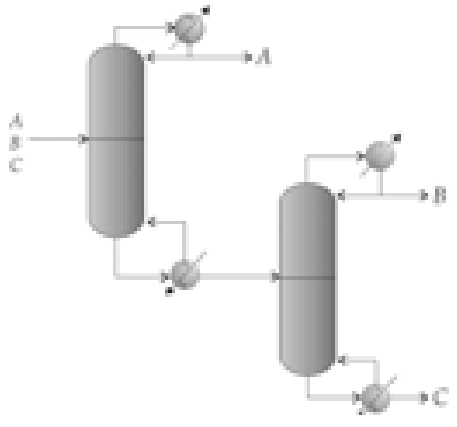

a) Direct Sequence

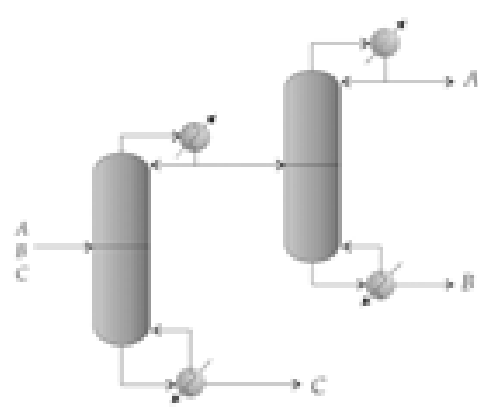

b) Indirect Sequence
Figure 2. Conventional distillation sequences for the separation of ternary mixtures

systems, TCDS (which is achieved through the implementation of interconnecting liquid and vapour streams between two columns) is considered to be more promising due to its potential savings in both energy and capital costs (Petlyuk et al., 1965; Finn, 1993). A good number of publications have been reported on TCDS structures, especially for ternary mixtures. The three TCDS schemes that have been studied more in detail are the system with a side rectifier (TCDS-SR, Figure 1a), the scheme with a side stripper (TCDS-SS, Figure 1b), and the fully thermally coupled distillation system (or Petlyuk column, Figure 1c). These schemes can offer energy savings of around $30 \%$ in contrast to the conventional distillation trains (Figure 2) widely used in the chemical industry for the separation of feeds with low or high content of the intermediate component (Tedder and Rudd, 1978; Glinos and Malone, 1988; Annakou and Mizsey, 1996; Yeomans and Grossmann, 2000). Most of these results were obtained through energy consumption calculations at minimum reflux conditions, and they spawned the development of more formal design procedures. Hernández and Jiménez (1996, 1999a) have reported the use of optimization strategies for TCDS schemes to detect designs with minimum energy consumption. TCDS options are more efficient because the remixing in the intermediate component, presented naturally in the conventional distillation sequences and translated into higher energy consumption, is reduced significantly, thus reducing energy requirements (Triantafyllou and Smith, 1992; Hernández et al., 2003). When comparing the energy savings of the integrated schemes, it has been found that in general the Petlyuk column offers better savings than the systems with side columns. Even though the Petlyuk column, the most important TCDS sequence, was introduced some 50 years ago (Brugma, 1937), its use has been limited because of potential control problems (Fidkowski and Krolikowski, 1990; Serra et al., 2003). Recent research efforts have been conducted to understand the operational properties of TCDS. The works of Wolff and Skogestad (1995), Abdul-Mutalib and Smith (1998), Hernández and Jiménez (1999b), Jiménez et al. (2001) and SegoviaHernández et al. (2002) have shown that some of these integrated options are controllable, so that their potential implementation would probably not be at the expense of control problems. Recently, motivated by the expected savings in both energy and capital investment, industrial implementations of TCDS in companies such as BASF have been reported (Kaibel and Schoenmakers, 2002).

It is important to mention that TCDS options have been used for the separation of hydrocarbon mixtures and air into oxygen, nitrogen and argon (Finn, 1993), but a common result is that important savings in energy can be obtained in contrast to conventional distillation sequences. The most used complex distillation sequence is the fully thermally coupled distillation sequence, or Petlyuk column, which can be implemented in industrial practice by using a divided-wall distillation column. BASF has implemented this Petlyuk-type column obtaining savings in both energy and capital costs. Also, Grossmann et al. (2005) have reported the use of mathematical programming for the synthesis of complex distillation columns for the separation of zeotropic and azeotropic mixtures. Their results show that significant energy savings can be obtained.

In this paper we present a comparative study of the energyefficiency performance between conventional distillation sequences and TCDS for the separation of ternary mixtures of hydrocarbons under the action of feedback control loops.

\section{DESIGN PROCEDURE}

The design and optimization of the conventional distillation sequences are well known. In this work the conventional distillation sequences (Figure 2) were designed and optimized using the process simulator Aspen Plus $11.1^{\mathrm{TM}}$. In the case of TCDS the design and optimization is more complicated because of recycle streams between the two distillation columns. The optimized design is obtained in two stages: (i) the conventional distillation sequences of Figure 2 were used to provide an initial tray structure; (ii) then, recycle streams were introduced between columns as indicated in Figure 1. For the TCDS-SR (Figure 1a), a vapour recycle (VF) stream is taken from the first column and introduced in the bottoms of the second column (removing the reboiler). The recycle stream was varied until minimum energy consumption in the reboiler of the first column was detected. For 


\begin{tabular}{|c|c|c|c|c|c|}
\hline Feed & Direct sequence & Indirect sequence & TCDS-SR & TCDS-SS & Petlyuk column \\
\hline \multicolumn{6}{|c|}{ Mixture M1 } \\
\hline $\mathrm{F} 1$ & 956.3 & 1039.3 & 738.6 & 800.0 & 500.9 \\
\hline F2 & 1209.2 & 1276.4 & 927.9 & 1028.9 & 627.8 \\
\hline \multicolumn{6}{|c|}{ Mixture M2 } \\
\hline F1 & 2177.2 & 2132.4 & 2082.3 & 2020.5 & 1846.0 \\
\hline F2 & 2290.2 & 2151.8 & 2072.6 & 2038.8 & 1799.8 \\
\hline \multicolumn{6}{|c|}{ Mixture M3 } \\
\hline $\mathrm{F} 1$ & 1139.0 & 1669.4 & 865.1 & 892.5 & 703.1 \\
\hline F2 & 1686.5 & 1553.0 & 1130.7 & 1118.2 & 762.1 \\
\hline
\end{tabular}

the TCDS-SS (Figure 1b), the recycle stream in the liquid phase (LF) is introduced in the top of second column, which removes the original condenser. Again, the recycle stream was varied until the minimum energy demand in the reboilers was detected. In the case of the Petlyuk column (Figure 1c) the tray structure was obtained from a sequence of a prefractionator followed by two binary distillation columns. Two recycle streams provide the full thermal coupling. The two recycle streams (LV and VF, see Figure 1c) were varied until the minimum energy consumption was obtained. TCDS structures require three design specifications in order to guarantee the purities in the products. The detailed design methods for the three TCDS options are reported in Hernández and Jiménez (1996, 1999a).

\section{DYNAMIC SIMULATIONS AND CASE STUDIES}

Although more formal techniques to select the control loops for the integrated columns may be used (for instance the relative gain array method), we based our selection on practical considerations. Thus, the control of the lightest component (A) was manipulated with the reflux flow rate, the heaviest component (C) with the reboiler heat duty, and the control of the intermediate component (B) was a function of the integrated structure; for the TCDS-SR it was tied to the reflux flow rate of the side rectifier, for the TCDS-SS to the heat duty of the side stripper, and for the Petlyuk column to the side product stream flow rate. The closed loop analysis was based on proportional-integral controllers. The parameters of the controllers, proportional gains $\left(\mathrm{K}_{\mathrm{C}}\right)$ and the reset times $\left(\tau_{\mathrm{i}}\right)$, were optimized for each conventional and integrated scheme using a minimization procedure of the integral of the absolute error (IAE). The case studies were selected to reflect different separation difficulties and different contents of the intermediate component of the ternary mixtures. Three mixtures with different values of ESI (the ratio of relative volatilities of the split $\mathrm{AB}$ to the split $\mathrm{BC}$, as defined by Tedder and Rudd, 1978) were considered. The selected mixtures were n-pentane, n-hexane and n-heptane (M1, ESI = 1.04), n-butane, isopentane and n-pentane (M2, ESI $=1.86)$, and isobutane, $n$ butane and n-hexane (M3, ESI $=0.18)$. To examine the effect of the content of the intermediate component, two types of feed compositions were assumed. One feed with a low content of the intermediate component (where mole fractions of $\mathrm{A}, \mathrm{B}, \mathrm{C}$, were equal to $0.40,0.20,0.40$, feed $F 1$ ) and another one with a high content of the intermediate component ( $\mathrm{A}, \mathrm{B}, \mathrm{C}$ equal to 0.15 , $0.70,0.15$, feed $F 2$ ), were used. The total feed flow rate for all cases was $100 \mathrm{lbmol} / \mathrm{h}$. Specified product purities of 98.7, 98 and 98.6 mole \% for A, B and C respectively were assumed.

\begin{tabular}{l|l|l|l|}
\hline \multicolumn{4}{|c|}{ Table 2. IAE results for mixture M1, composition F1 } \\
\hline Sequence & Component A & Component B & Component C \\
\hline Direct & $7.92441 \times 10^{-3}$ & $5.28568 \times 10^{-2}$ & $2.95796 \times 10^{-3}$ \\
\hline Indirect & $4.0076 \times 10^{-3}$ & $3.4576 \times 10^{-3}$ & $2.64873 \times 10^{-3}$ \\
\hline TCDS-SR & $3.55963 \times 10^{-3}$ & $2.78147 \times 10^{-3}$ & $7.99529 \times 10^{-4}$ \\
\hline TCDS-SS & $7.69839 \times 10^{-4}$ & $8.9876 \times 10^{-3}$ & $3.80888 \times 10^{-4}$ \\
\hline Petlyuk & $1.74924 \times 10^{-4}$ & $3.42972 \times 10^{-4}$ & $2.10607 \times 10^{-4}$ \\
\hline
\end{tabular}

\section{ENERGY DEMANDS}

The results on energy requirements were obtained after the optimization procedure described earlier was carried out on the recycle streams for the three integrated sequences. Table 1 shows the energy requirements for each integrated scheme and conventional sequence. When mixture M1 was considered, the Petlyuk system showed the best potential, offering savings in energy consumption of up to $50 \%$ with respect to the conventional distillation sequences. The TCDS-SR and TCDS-SS sequences required between 14 and $20 \%$ less energy consumption than the conventional sequences. The superior behaviour on energy efficiency of the Petlyuk column was also observed for mixtures M2 and M3 (Table 1). In the case of mixture M2 the Petlyuk column can offer savings in energy consumption of up to $15 \%$ with respect to the conventional sequences, while the savings achieved by the TCDS-SR and TCDS-SS schemes are in the order of $10 \%$. In the case of mixture M3 the Petlyuk column requires between 40 and $50 \%$ less energy consumption, whereas the TCDS-SR and the TCDS-SS options offered energy savings of up to $30 \%$ with respect to the conventional sequences. In general, the Petlyuk column showed the highest energy savings with respect to the direct and indirect conventional distillation sequences for all the case studies considered.

\section{ENERGY-EFFICIENCY DYNAMIC PERFORMANCE}

The dynamic performance of the energy-efficient designs of TCDS was analyzed following the responses to set point changes for product composition on each of the three product streams. The three control loops for each conventional and TCDS were assumed to operate under closed loop operation.

\section{Mixture M1}

The IAE values obtained (feed F1) for each composition control loop of the distillation sequences under analysis is showed in Table 2. It is observed that the Petlyuk column offers the best 


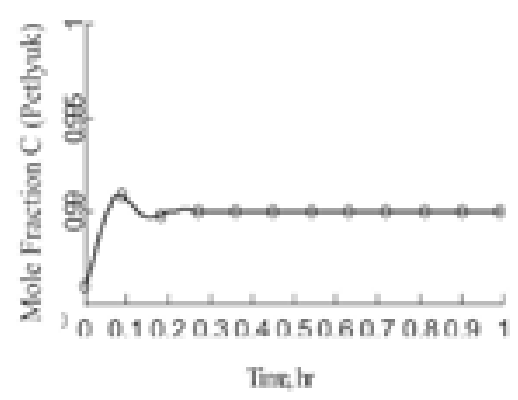

a) Component C (Petlyuk)

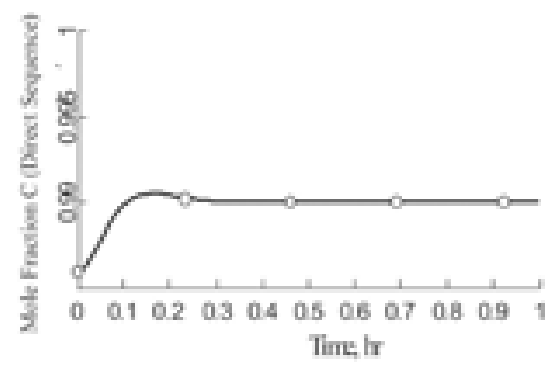

d) Component C (Direct Sequence)

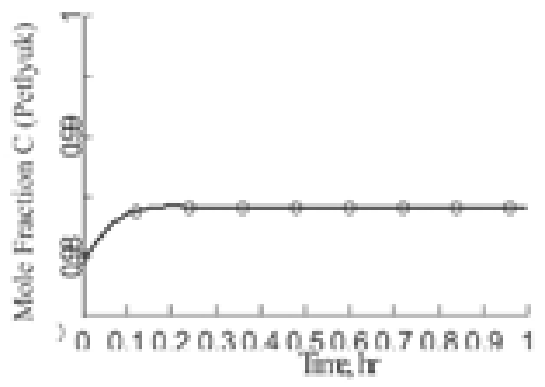

b) Component B (Petlyuk)

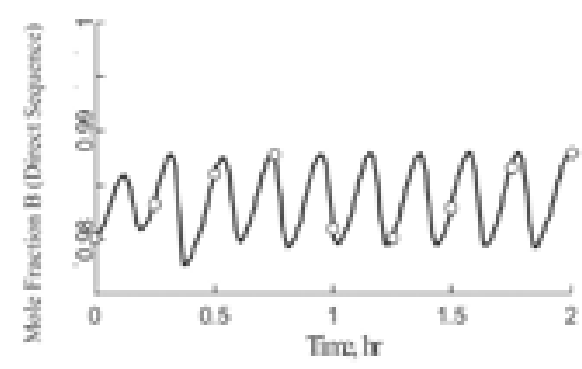

e) Component B (Direct Sequence)

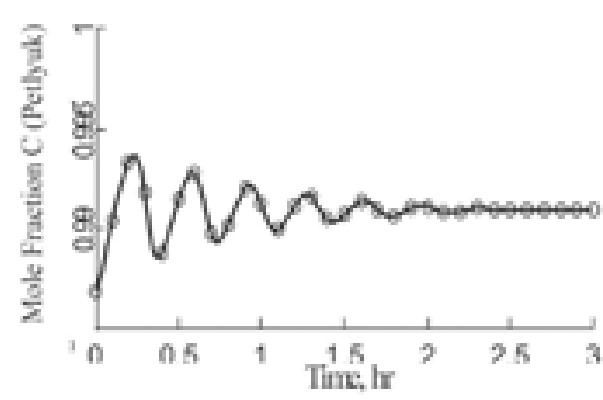

c) Component A (Petlyuk)

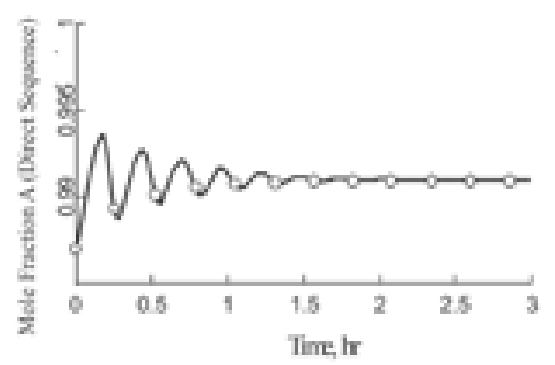

f) Component A (Direct Sequence)

Figure 3. Dynamic responses of the Petlyuk column and the direct sequence (M1, F1)

dynamic behaviour, which is reflected in the lowest values of IAE, for the control of the three product streams. The dynamic response of each control loop when the Petlyuk column was considered is displayed in Figure 3, where a comparison is made to the response of the widely-used direct distillation sequence. One may notice in particular how the direct sequence is unable to control the composition of the intermediate component, while the Petlyuk column provides a smooth response, with a relatively short settling time. It is interesting to notice that for this mixture with an ESI $=1$ and a low content of the intermediate component in the feed, the Petlyuk column offers the highest energy savings and also shows the best dynamic performance from the five distillation sequences under consideration. When the content of the intermediate component in the feed was raised from 20 to $70 \%$ (feed F2), significant changes in the dynamic responses of the distillation systems were observed. The first remark is that the Petlyuk column does not provide the best choice from an operational point of view. A second observation is that the best choice depends on the control loop of primary interest. When the control of the light (A) or the heavy (C) component of the ternary mixture is of primary concern, then the TCDS-SS scheme provides the best option since it offers the lowest IAE values for these control loops. However, if the control policy calls for the composition of the intermediate (B) component, the indirect sequence shows the best behaviour, with the lowest value of IAE. Overall, it may be stated that for this type of mixture, the TCDS-SS may offer a good compromise, providing energy savings with respect to conventional sequences and good dynamic properties. In these cases, the control valves showed a quick adjustment towards the new steady state of the manipulated variables, which may also be interpreted as a lower energy consumption (in other words, lower control effort) in the dynamic behaviour of the sequences.

\section{Other Mixtures}

The analysis was completed with the consideration of the other four cases of studies. Some trends were observed (Tables 3 and 4). For one thing, the best option depends on the amount of intermediate component. Also, it was found that the best sequence, based on the IAE criterion, for the control of the light component was also the best choice for the control of the heavy component, but a different separation scheme provided the best option for the control of the intermediate component. If the feed contains low amounts of the intermediate component, the Petlyuk column shows the best dynamic behaviour for the control of the light and heavy components, while the indirect sequence provides the best responses for the control of the intermediate component. For feed mixtures with high content of the intermediate component, sequences with side columns showed the best responses for the control of light and heavy components, and conventional sequences were better for the control of the intermediate component. The ease of separability index also shows some effect on the topology of the preferred separation scheme when the feed contains a high amount of the intermediate component. For mixtures with ESI higher than 1, the systems with two bottom streams (integrated or conventional) show the best dynamic properties, while for mixtures with ESI lower than 1, the separation systems with two top distillate streams (TCDS-SR or the direct sequence) provide the best dynamic responses, which may also be interpreted as a lower energy consumption (the control valves show a quick adjustment towards the new steady state). Finally, we consider the Petlyuk type column, or 


\begin{tabular}{|l|l|l|l|}
\hline \multicolumn{4}{|c|}{ Table 3. IAE results for mixture M2, composition F1 } \\
\hline Sequence & Component A & Component B & Component C \\
\hline Direct & 0.00187781 & 0.010187 & 0.00144499 \\
\hline Indirect & $1.6439 \times 10^{-4}$ & $3.61135 \times 10^{-5}$ & 0.0094768 \\
\hline TCDS-SR & $4.64586 \times 10^{-5}$ & 0.0053059 & $3.2677 \times 10^{-4}$ \\
\hline TCDS-SS & 0.0128428 & 0.0244571 & $8.92827 \times 10^{-4}$ \\
\hline Petlyuk & $3.25178 \times 10^{-5}$ & 0.00164826 & $1.2647 \times 10^{-4}$ \\
\hline
\end{tabular}

From energy considerations the Petlyuk column was shown to provide in general the best option. Although the results from the dynamic analysis do not show a dominant option, some trends were observed. One factor that affects the feedback behaviour of the distillation systems is the amount of intermediate component, and the other one is the control point under consideration. Integrated sequences showed a better feedback behaviour when the control points were set at the lightest of the heaviest component. For these cases, the influence of the amount of intermediate component as follows; the Petlyuk column performed better for feed mixtures with a low amount of component $\mathrm{B}$, while the sequences with side columns provided the best dynamic performance when the amount of the intermediate component was high. When the control was focused on the intermediate component, the results changed noticeably since the conventional sequences performed better than the integrated options. The results of the study have shown that the incentive for the use of TCDS, provided by their lower energy requirements, should not be overlooked in the face of their dynamic properties. The lower control efforts required by TCDS for some of the case studies indicate that these options may also provide a more efficient use of energy during its transient times.

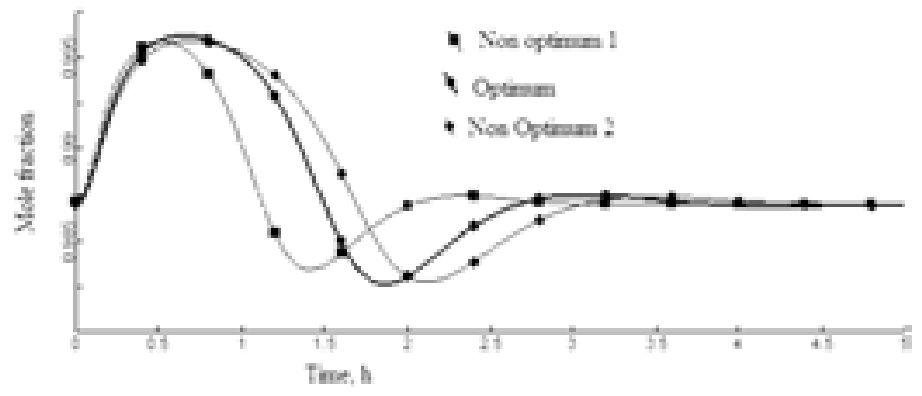

Figure 4. Dynamic responses of component A of the TCDS-SR, for a disturbance in the feed composition for three base designs

divided-wall column, which has been used in industrial practice. It has been reported by Serra et al. (2003) that the dynamic properties of the Petlyuk column can be improved by operating at non-optimal conditions, i.e., not minimized the energy consumption in the reboiler. In this sense, it is clear the trade off between controllability properties and energy consumption. Better conditioned designs can be obtained by degrading the energy consumption. This behaviour can be observed in the other two thermally coupled distillation sequences; for example, for the case of the TCDS-SR, three base designs are considered: (i) optimum energy consumption; (ii) $10 \%$ higher than the optimum energy consumption (non-optimum 1); and (iii) $20 \%$ higher than the optimum energy consumption (non-optimum 2) can be studied for a disturbance in the feed composition (mole fraction of component $\mathrm{A}$ is increased $5 \%$ and components $\mathrm{B}$ and $\mathrm{C}$ are decreased $2.5 \%$ each one). For this disturbance, Figure 4 shows that the dynamic response in the non-optimum 1 is better that those obtained for the other two designs. This result needs to be taken into account in the design stage in order to guarantee better dynamic properties.

\section{CONCLUSIONS}

We have conducted an analysis on the energy efficiency of five distillation sequences for the separation of ternary mixtures, along with a preliminary study on their dynamic performance. Three of the sequences considered make use of thermal coupling, while the other two were the conventional direct and indirect sequences.

\section{NOMENCLATURE}

$\mathrm{ABC}$ ternary mixture

A light component

B intermediate component

C heavy component

ESI easy of separation index

IAE integral of the absolute error

LF interconnecting liquid flow

TCDS thermally coupled distillation sequences

\section{REFERENCES}

Abdul-Mutalib, M. I. and R. Smith, "Operation and Control of Dividing Wall Distillation Columns. Part I: Degrees of Freedom and Dynamic Simulation,” Trans Inst. Chem. Eng. 76, 308 (1998).

Annakou, O. and P. Mizsey, "Rigorous Comparative Study of Energy-Integrated Distillation Schemes,” Ind. Eng. Chem. Res. 35, 1877 (1996).

Brugma, A. J., "Fractional Distillation of Liquid Mixtures," Holanda, Patente No. 41, 850 (Oct. 15, 1937).

Fidkowski, Z. and L. Krolikowski, "Energy Requirements of Nonconventional Distillation Systems," AIChE J. 36(8), 1275 (1990).

Finn, A., "Consider Thermally Coupled Distillation," Chem. Eng. Prog. 41 (Oct. 1993).

Glinos, K. and M. F. Malone, "Optimality Regions for Complex Column Alternatives in Distillation Systems," Chem. Eng. Res. Des. 66, 229 (1988).

Grossmann, I. E., P. A. Aguirre and M. Barttfeld, "Optimal Synthesis of Complex Distillation Columns using Rigorous Models," Comput. Chem. Eng. 29(6), 1203-1215 (2005).

Hernández, S. and A. Jiménez, "Design of Optimal ThermallyCoupled Distillation Systems Using a Dynamic Model," Trans Inst. Chem. Eng. 74, 357 (1996).

Hernández, S. and A. Jiménez, "Design of Energy-Efficient Petlyuk Systems,” Comput. Chem. Eng. 23, 1005 (1999a). Hernández, S. and A. Jiménez, "Controllability Analysis of Thermally Coupled Systems,” Ind. Eng. Chem Res. 38(10), 3957 (1999b). 
Hernández, S., S. Pereira-Pech, A. Jiménez and V. RicoRamírez, "Energy Efficiency of an Indirect Thermally Coupled Distillation Sequence,” Can. J. Chem. Eng. 81(5) 1087 (2003).

Kaibel, G. and H. Schoenmakers, "Process Synthesis and Design in Industrial Practice,” European Symp. on Computer-Aided Proc. Eng. -12 Proc., Elsevier (2002).

Jiménez, A., S. Hernández, F. A. Montoy and M. Zavala-García, "Analysis of Control Properties of Conventional and Nonconventional Distillation Sequences,” Ind. Eng. Chem. Res. 40, 3757 (2001).

Petlyuk, F. B., M. Platonov and D. M. Slavinskii, "Thermodynamically Optimal Method for Separating Multicomponent Mixtures,” Int. Chem. Eng. 5(3), 555 (1965).

Segovia-Hernández, J. G., S. Hernández and A. Jiménez, "Control Behaviour of Thermally Coupled Distillation Sequences,” Trans Inst. Chem. Eng., 80, 783 (2002).

Serra, M., A. Espuña and L. Puigjaner, "Controllability of Different Multicomponent Distillation Arrangements,” Ind. Eng. Chem. Res. 42, 1773 (2003).

Tedder, D. W. and D. F. Rudd, "Parametric Studies in Industrial Distillation: Part I. Design Comparisons,” AIChE J. 24, 303 (1978).

Triantafyllou, C. and R. Smith, "The Design and Optimization of Fully Thermally Coupled Distillation Columns," Trans Inst. Chem. Eng. 70, 118 (1992).

Wolff, E. and S. Skogestad, "Operation of Integrated Three Products (Petlyuk) Distillation Columns,” Ind. Eng. Chem. Res. 34(6), 2094 (1995).

Yeomans, H. and I. Grossmann, "Optimal Design of Complex Distillation Columns Using Rigorous Tray-by-Tray Disjunctive Programming Models,” Ind. Eng. Chem. Res. 39 (11), 4326 (2000).

Manuscript received March 3, 2005; revised manuscript received October 25, 2005; accepted for publication November 7, 2005. 